\title{
Location, existence, and quantification in Turkish: What do results from a forced choice scale show?
}

Engin Arik ${ }^{1}$, Beril T. Arik ${ }^{2}$

${ }^{1}$ Psychology, Isik University, Turkey

2English, Purdue University, USA

https://doi.org/10.36505/ExLing-2012/05/0004/000210

\begin{abstract}
Previous research has shown that Turkish speakers' acceptability judgments differ with respect to the type of quantification of nouns and the introduction of new vs. old information in locatives and existentials. The present study tested these findings by asking participants to make a choice between locatives and existentials in which nouns were quantified. With Cochran Q then McNemar tests, we found that Turkish participants preferred existential sentences over locative sentences due to new vs. old information; number quantification over bare or plural nouns in existential sentences. These findings together provide additional evidence for the distinction between locatives and existentials.
\end{abstract}

Key words: locatives, existentials, quantification, Turkish

\section{Introduction}

Previous studies showed that locatives ('a book is on the table'), existentials ('there is a book on the table'), and possessives ('I have a book (on the table)') are cognitively and linguistically related to each other (Lyons 1967, Clark 1978, Freeze 1992, Jackendoff 1990, Heine 1997). Yet, they differ from one another in that existential sentences may contain a verb related to locative 'to be' and possessive 'to have,' contain a pivot, and a locative expression, and existential sentences obey definiteness restriction. In this study, by using a forced choice scale, we explored whether locatives and existentials in Turkish can further be distinguished from one another.

As expected, Turkish locatives and existential are related to each other. Locatives consist of NP and NP+locative+(Tense)+Person,number whereas existentials consist of an optional $(\mathrm{NP}+\text { locative) })_{\text {coda }}$ and $\mathrm{NP}_{\text {pivot }}$ as well as 'var'+(Tense)+Person,number. We give two examples for these constructions below.

(1) [Kitap $]_{\text {theme }}$ kutu-nun iç-in-de-y-di- Ø. (locative)

Book box-gen in-poss-loc-copula-past-3sg

'The book was in the box'

(2) Kutu-nun iç-in-de $]_{\text {coda }} \quad$ kitap $]_{\text {theme-pivot }} \quad$ var-(y)d1- $\varnothing$. (existential)

Box-gen in-poss-loc book exist-copula-past-3sg

'There was a book in the box'

ExLing 2012: Proceedings of 5th Tutorial and Research Workshop on Experimental Linguistics, 27-29 August 2012, Athens, Greece 
We had conducted a series of studies employing experimental linguistic methodologies to explore the relationship between locatives and existentials. By using Likert scales, we asked participants to rate locative and existential sentences in which noun phrases in a theme role, e.g., kitap 'book' in (1) and (2), were quantified (bare kitap 'book' or number quantified iki kitap 'two books' or plural kitaplar 'books') (Arik 2011). The results showed that overll, the ratings for the existential sentences were significantly higher than the ratings for the locative sentences. There was no main effect of quantification type. But there was a significant interaction between sentence type and quantification type. One reason for this finding could be because of new vs. old information: Existentials but not locatives introduce new information therefore participants could have rated existentials higher than locatives. To test this hypothesis, we conducted another study (Arik 2012) in which each testing item had two sentences: The first one was either locative or existential while the second one that followed was adjectival to make the theme in the first sentence as new information. For example, 'There is a book on the table. The book is thick'. We obtained similar results: the ratings for the existential sentences were significantly higher than the ratings for the locative sentences. There was no main effect of quantification type meaning that the participants did not rate the sentences differently due to the manipulations at the NP level only. But there was a significant interaction between sentence type and quantification type which suggests that both the manipulations at the NP level and the use of either an existential sentence or a locative sentence led to a change in the ratings.

These findings together indicated that the Turkish speakers' acceptability judgments differ with respect to the structure of NPs and the introduction of new vs. old information in Turkish locatives and existential. In the present study, we further tested our findings by employing another experimental linguistic methodology, forced choice scales.

\section{Methodology}

Sixty native speakers of Turkish participated in this study. We used a forcedchoice scale with a $2 \times 3$ within-subjects design to get acceptability judgments from the participants. The first factor was construction: Locative vs. Existential; the second factor was Quantification of noun in the theme role: Bare vs. Plural vs. Number quantification. There were two scripts with 24 items (12 testing items with 2 sets and 12 fillers). One of the scripts contained items in reverse order of the other script to avoid the order effect. Each item had two columns in which either locative or existential sentence was presented on a single paper. 
Participants were asked to pick one item over another, e.g. (3) or (4):

(3) Kitap masanın üstünde. Kitap kalın. (Locative, Bare noun)

'A/The book is on the table. The book is thick.'

(4) Masanın üstünde kitap var. Kitap kalın. (Existential, Bare noun)

'There is a/the book on the table. The book is thick.'

\section{Results}

Descriptive statistics of the measures are given in Table 1. With a Cochran Q's test, we found that there was a significant difference $(\chi 2(5)=94.57$, $\mathrm{p}<.001)$. A pairwise comparison between these factors with McNemar test showed significant differences between locatives (existential preference, 95.3\%) and existentials (existential preference, $73.3 \%$ ) due to new vs. old information; between bare nouns (existential preference, $80.4 \%$ ) and number quantified nouns (existential preference, 91.3\%); and, between number quantified nouns and plural nouns (existential preference, $81.2 \%$ ) but no significant difference between bare nouns and plural nouns due to definiteness/specificity effect.

Table 1. Percentages of participants' choices with respect to given testing items.

\begin{tabular}{|l|c|c|}
\hline Testing item on the left column & Locative choice & Existential choice \\
\hline Locative, Bare noun & $8 \%$ & $91 \%$ \\
\hline Existential, Bare noun & $29 \%$ & $71 \%$ \\
\hline Locative, Number quantified noun & $1 \%$ & $98 \%$ \\
\hline Existential, Number quantified noun & $15 \%$ & $84 \%$ \\
\hline Locative, Plural noun & $3 \%$ & $96 \%$ \\
\hline Existential, Plural noun & $34 \%$ & $65 \%$ \\
\hline
\end{tabular}

\section{Conclusion}

Previous research (Arik 2011, 2012) indicated that the Turkish speakers' acceptability judgments differ with respect to the type of quantification in NPs in theme roles and the introduction of new vs. old information in Turkish locatives and existentials. The current study provided additional evidence to support this distinction. This distinction could be because of a DP/NP syntactic distinction, a definiteness/specificity interpretation, new vs. old information (Milsark 1974, Erguvanli-Taylan 1987, Enc 1991, McNally 1992, Kornfilt 1997, Zucchi 2005, Öztürk 2005, Nakipoglu 2009) in 
locatives and existentials. Future research will investigate other types of noun modification such as color and quality to further explore this topic.

\section{Acknowledgements}

This study supported in part by Işı University scientific research grant (BAP-12A103).

\section{References}

Arik, E. 2011. An experimental investigation of Turkish locatives and existentiall. Book of Abstracts of the 20th International Symposium on Theoretical and Applied Linguistics. Aristotle University of Thessaloniki.

Arik, E. 2012. Location and existence in Turkish from an experimental linguistic perspective. Proceedings Book of the International Symposium on Language and Communication, 395-406. Erzurum, Meta Press.

Clark, E. V. 1978. Locationals: A study of 'existential,' 'locative,' and 'possessive' sentences. In J. H. Greenberg (Ed.) 1978, Universals of human language, vol. 4: Syntax, 85-126. Stanford, CA, Stanford University Press, 1978.

Enc, M. 1991. The semantics of specificity. The Linguistic Inquiry, 22, 1, 1-25.

Freeze, R. 1992. Existentials and other locatives. Language, 68, 3, 553-595.

Heine, B. 1997. Possession: Cognitive Forces, Sources, and Grammaticalization. Cambridge, UK, Cambridge University Press.

Jackendoff, R. 1990. Semantic Structures. Cambridge, MA, The MIT Press.

Kornfilt, J. 1997. Turkish. New York, Routledge.

Lyons, J. 1977. Semantics. Cambridge, UK, Cambridge University Press.

McNally, L. 1992. An interpretation for the English existential construction. Unpublished PhD Dissertation, UCSC.

Milsark, G. 1974. Existential Sentences in English. Unpublished PhD Dissertation, MIT.

Nakipoğlu, M. 2009. The semantics of the Turkish accusative marked definites and the relation between prosodic structure and information structure. Lingua. 119, 9, 1253-1280.

Öztürk, B. 2005. Case, referentiality, and phase structure (Linguistik Aktuell 77). Amsterdam, John Benjamins.

Taylan, E. E. 1987. The Role of Semantic Features in Turkish Word Order. Folio Linguistica 21, 2-4, 215-229.

Zucchi, A. 1995. The ingredients of the definiteness and the definiteness effect. Natural Language Semantics, 3, 33-7. 